\title{
VESTIBOLOGY
}

\section{Uphill/downhill nystagmus}

\section{Nistagmo in salita e nistagmo in discesa}

\author{
M. GUFONI \\ Department of Otorhinolaryngology, Spedali Riuniti Livorno, Italy
}

\section{SUMMARY}

Differential diagnosis between peripheral and central spontaneous nystagmus can be difficult to classify (as peripheral or central) even on the basis of criteria recommended in the recent literature. The aim of this paper is to use the combination of spontaneous nystagmus and ocular tilt reaction to determine the site of origin of the disease that causes nystagmus. We propose to classify the nystagmus in: 1) "Uphill" nystagmus in which the nystagmus takes on an inclined plane and the direction of the fast phase is towards the hypertropic eye (this type of nystagmus is likely peripheral); 2) "Downhill" nystagmus when the nystagmus beats toward the hypotropic eye (this type of nystagmus is likely central); 3) "Flat" nystagmus when the plane on which nystagmus beats is perfectly horizontal: in this case, we cannot say anything about the site of lesion (it was only detected in $15 \%$ of cases). The spatial position of nystagmus vector has to be considered as an intrinsic characteristic of the nystagmus itself (as direction, frequency, angular velocity etc.) and must be reported in the description, possibly giving an indication of the site of damage (peripheral or central). In particular, similar results are obtained by comparing the inclination of the nystagmus with the head impulse test (HIT, considered the best bedside test now available). It seems that this sign may confirm HIT for safer diagnosis or replace it in case of doubt. In contrast, in case of "Flat" nystagmus (probably attributable to the fact that the utricular maculae are spared), HIT can replace observation of the plane of the nystagmus. Thus, the two signs confirm and integrate each other. The test does not require additional time and is not tedious for the patient. It is proposed that it be included in the evaluation of spontaneous nystagmus in everyday clinical practice.

KEY WORDS: Vertigo $\bullet$ Nystagmus $\bullet$ Ocular tilt reaction $\bullet$ Utriculus $\bullet$ Semicircular canal

\section{RIASSUNTO}

Capita spesso che un paziente con vertigini sia difficilmente inquadrabile (se periferico o centrale), anche affidandosi ai criteri consigliati nella recente letteratura. In questo lavoro si propone di utilizzare la valutazione della combinazione tra nistagmo spontaneo ed "Ocular Tilt Reaction" per dare un giudizio sulla sede della patologia che provoca il nistagmo. Si propone di dividere il nistagmo in : 1) nistagmo "in salita" in cui il nistagmo batte su un piano inclinato e il verso della fase rapida è verso l'occhio ipertropico (questo tipo di nistagmo è verosimilmente periferico); 2) nistagmo "in discesa" " in cui il nistagmo batte verso l'occhio ipotropico (questo tipo di nistagmo è verosimilmente centrale); 3) nistagmo "in piano" " in cui il piano su cui batte il nistagmo è perfettamente orizzontale e sul quale non si può dire nulla (è stato rilevato solo nel 15\% dei casi). La posizione nello spazio del vettore del nistagmo è da considerare una caratteristica intrinseca del nistagmo stesso (come direzione, verso ,frequenza, velocità angolare ecc.) e va riportata nella descrizione del nistagmo, potendo dare un'indicazione sulla sua natura (periferico o centrale). In particolare, confrontando l'inclinazione del nistagmo con l'Head Impulse Test (HIT), si ottengono risultati simili nella valutazione topodiagnostica di un nistagmo spontaneo. Sembra dunque che questo segno possa confermare l'HIT per una diagnosi più sicura o sostituirlo in casi dubbi. Al contrario, in caso di nistagmo che batte in piano (né in salita né in discesa, attribuibile probabilmente al fatto che le macule utriculari sono risparmiate) l'HIT può sostituire l'osservazione del piano del nistagmo. In questo modo i due segni si confermano e si integrano a vicenda nei casi dubbi. Il test non richiede tempi aggiuntivi e non è in alcun modo causa di disturbo per il paziente, per cui se ne propone l'inserimento nella valutazione di ogni nistagmo spontaneo.

PAROLE CHIAVE: Vertigine $\bullet$ Nistagmo $\bullet$ Ocular tilt reaction $\bullet$ Utriculo $\bullet$ Canale semicircolare

Acta Otorhinolaryngol Ital 2017;37:513-518

\section{Introduction}

Vertigo is a widespread problem and one of the most common reasons for medical consultation in Emergency Departments. Even in Italy, in a recent study, $40.3 \%$ subjects reported at least one episode of vertigo/dizziness during their lifetime; $71.3 \%$ were females, and $28.7 \%$ were males, confirming the high prevalence of these symptoms in the general population.
In emergency rooms a diagnosis is requested as rapid and accurate as possible, but sometimes it can be difficult to distinguish central (and possibly dangerous) from peripheral cases ${ }^{1}$.

Anyway, as far as possible, a spontaneous peripheral nystagmus should not be confused with a central one.

For this purpose, the recent literature suggests few signs which seem more accurate than imaging ${ }^{2}$ :

1. Head impulse test. A pathological test toward the af- 
fected side (at least one correction saccadic movement) addresses toward a peripheral problem. A normal test (no corrective saccades at all) may be related to central damage $^{34}$.

2. Romberg test. A peripheral patient is able to keep standing without support, while a central patient needs help to avoid falling down ${ }^{5}$.

3. Associated neurological signs (gaze evoked, direction changing or positional nystagmus, specific cerebellar or medulla signs) aim towards a diagnosis of centrality ${ }^{6}$.

4. Quick recovery: a peripheral patient is expected to recover soon after the event.

5. Unilateral weakness seems suggestive of a peripheral pathology ${ }^{7}$.

6. Pathologic cover test is considered a sign of central vestibular disorder as associated with ocular tilt reaction.

Unfortunately, none of these signs taken alone allows certain diagnosis:

1. HIT may be difficult to perform in acute vertigo and covert saccades can be misleading ${ }^{8}$.

2. Imbalance grade is not highly specific and has rather low sensitivity ${ }^{7}$.

3. In early stages, a spontaneous nystagmus after a cerebellar stroke may mimic a peripheral nystagmus with no other central sign.

4. The recovery trend is evident after some days, which is too late: diagnosis is expected as soon as possible and clinical evolution is (hopefully) only a confirmation of the previous diagnosis.

5. Bithermal caloric test may not be available for everyone and everywhere.

6. Ocular tilt reaction can be present even with normal cover test.

Thus, the efficiency of this standard can depend on a single sign.

The aim of this work is to evaluate ocular tilt reaction (OTR), and not just cover test, as a means of diagnosis for a spontaneous nystagmus.

In case of utricular macula damage an OTR is generated, with three components:

1. Head tilted toward the injured ear.

2. Hypotropia of the eye on the side of the damaged ear.

3. Eye balls torsion (counterclockwise in case of right utriculus deficit, by the examiner point of view) ${ }^{9}$.

The utricular afferent pathways cross the midline in the pons. Consequently, three different conditions are expected:

1. Utricular peripheral dysfunction: in this case, the hypotropic eyeball is homolateral to the lesion.

2. Central pathway dysfunction, before the crossing of fibres: even in this case the hypotropic eye is homolateral to the lesion.

3. Central pathway lesion after fibre crossing: in this case, the hypotropic eye is contralateral to the lesion because the injured fibres are coming from the opposite side and are to be referred to the opposite utricle.
The cerebellum is thought to apply an ipsilateral inhibition, so the result of cerebellar suffering would be an OTR toward the intact side (as a consequence of lack of inhibition) ${ }^{10}$. Thus, two types of OTR can be expected:

1. A peripheral form (the lower eye is ipsilateral to the lesion).

2. A central form (the lower eye is contralateral to the lesion).

A peripheral OTR is associated with lesions of the utricular receptor and afferent fibres until crossing.

Indeed, a lesion of the central pathway until crossing is impossible to distinguish from a peripheral lesion of the utricle, if no other signs of brain stem suffering are clinically appreciable.

This situation is reminiscent of the case in which a lesion occurs in the root entry zone of the vestibular nerve: the lesion is central from an anatomical point of view, but it is functionally peripheral.

With regards to the vestibular patient in the acute phase, three possibilities may be considered:

1. Labyrinthine deficit, including lateral semicircular canal and utricular macula.

2. Central utricular pathways injury (including medulla and/or cerebellum) associated with a central deficit sustaining spontaneous nystagmus.

3. No utricular (or utricular pathways) lesion.

In case 1), a spontaneous nystagmus would be expected towards the healthy side and an OTR on the affected side. The eye on the side of the affected ear is undermost with respect to the contralateral one: as a consequence, nystagmus is directed towards the uppermost ear ("Uphill nystagmus", Fig. 1).

In case 2), a spontaneous nystagmus would be expected towards the healthy side, but an OTR on the right side. The eye on the side of the damage is uppermost with respect

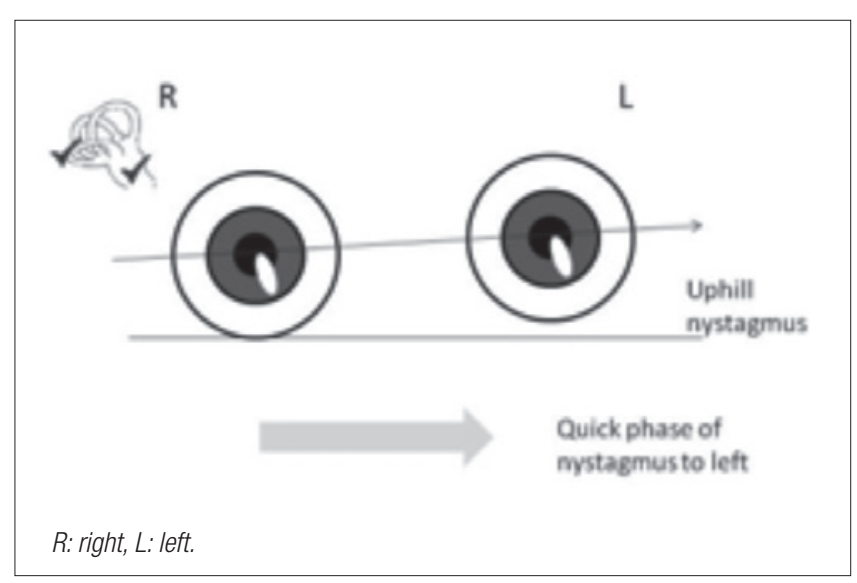

Fig. 1. The right lateral semicircular canal is damaged and a spontaneous horizontal nystagmus arises to the left. At the same time, right utriculus is injured (by the same disease) and an ocular tilt reaction is present, with hypotropia of the right eye. As a result, the plane on which nystagmus beats is inclined upward ("uphill"). 
of that of the other side and nystagmus is directed towards the undermost eye ("Downhill nystagmus", Fig. 2).

In case 3), an OTR cannot be expected. Eyes stand on the same line and nystagmus maintains in the horizontal plane (possibly with a rotatory component not due to the maculae, "Flat nystagmus", Fig. 3).

This aspect can be useful for the differential diagnosis between peripheral and central spontaneous nystagmus (Fig. 4).

To evaluate this sign, the direction (uphill, downhill, horizontal) of nystagmus was confronted with the presence/ absence of a corrective saccade in the HIT, which is considered the best bedside evaluation test now available.

\section{Materials and methods}

65 patients were included after randomisation and exclusion of unsuitable cases (mean age 59, range 21 to 91 ,

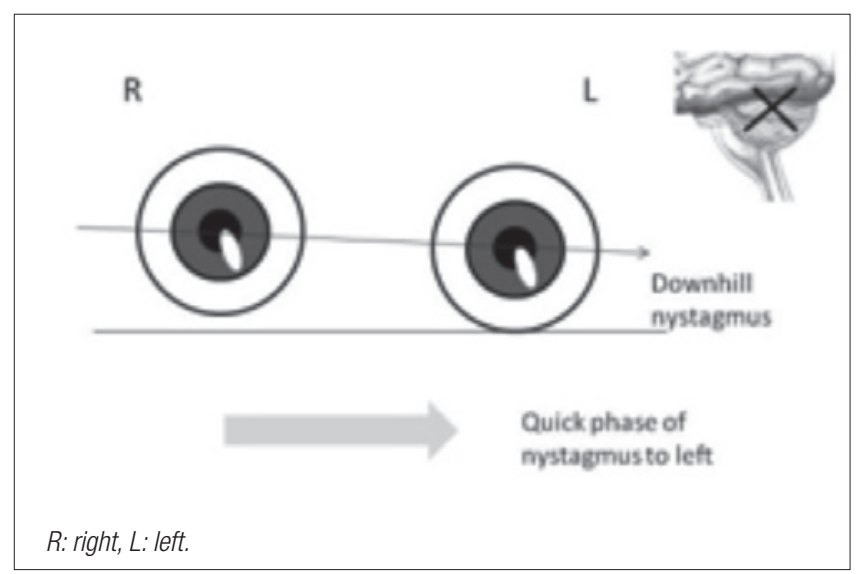

Fig. 2. A lesion is present after decussation of the utricular afferent fibres. Ocular tilt reaction is referred to the opposite side. The (central) resulting nystagmus is tilted "downhill".

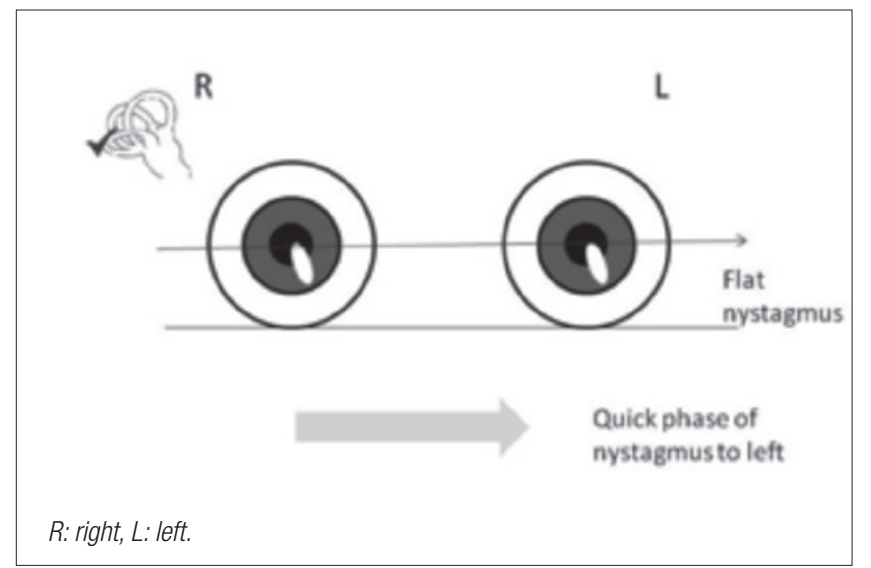

Fig. 3. The right lateral semicircular canal is damaged and a spontaneous horizontal nystagmus arises directed to the left, but the right utriculus is spared. As a result, the plane on which nystagmus beats is horizontal ("flat" nystagmus).

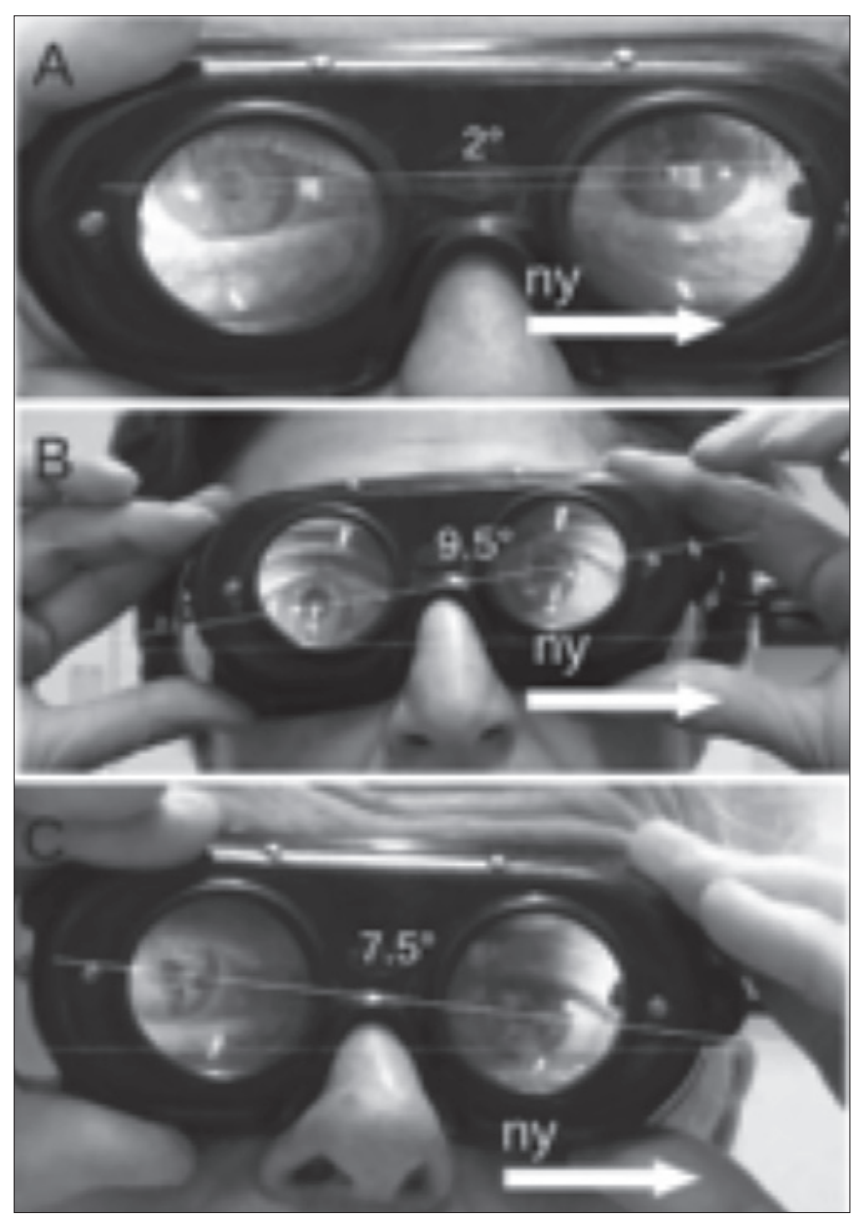

Fig. 4. "Flat" (unknown) nystagmus (A) , "Uphill" (peripheral) nystagmus (B), "Downhill" (central) nystagmus (C).

32 males and 33 females) sent from the Emergency Department for acute rotatory vertigo in the period from $1 / 1 / 2012$ to $31 / 12 / 2013$.

Apart from the nystagmus, no signs were found by neurological examination performed in emergency room.

After careful history, patients were examined by otoscopy, pure tone audiometry (if this was impossible for the conditions of the patient, a bedside screening was obtained ${ }^{11}$ ) and evaluation of spontaneous, gaze, rebound, positional and positioning nystagmus.

Furthermore, HIT and the ability to remain standing alone were observed.

Finally, patients were examined for neurological (and especially cerebellar) signs.

A second researcher was asked to evaluate the skew deviation and to report the possible presence of an hypotropic eye. For this task, the patient, wearing Frenzel glasses, was sitting without leaning.

Patients diagnosed as central were referred back to the Emergency Department to complete examinations, the others were treated with symptomatic drugs (usually antiemetics, antihistamines, or benzodiazepines) and rechecked after one day and three days. 
Exclusion criteria were:

- previous medical treatment;

- known eye motility disorders;

- stiff neck;

- presence of previous audiological, vestibular, neurological diseases.

Only patients with horizontal spontaneous nystagmus were considered.

Excluded patients underwent the same tests and treatments as the others, but were not considered for statistical purposes.

At day 1 some improvement, even if slight, was expected, otherwise the patient was reconsidered as central.

On the third day, a bithermal caloric test was performed (after Fitzgerald-Hallpike), and evaluation of unilateral weakness and directional preponderance were obtained (applying Jongkees formulas).

\section{Results}

The direction of nystagmus (beating on a plane tilted toward the hypotropic or hypertropic eyeball) was compared with the HIT, considered as the gold standard in patients with spontaneous nystagmus. The rate of congruence of the two tests is reported in Table I and Table II.

In 32 cases, the quick phase of nystagmus was directed to the right, and in 33 cases to the left. In 10 of 65 cases (about 15\%), a tilt direction of nystagmus (with respect to the horizon) was not detected.
In 10 of 65 cases (about 15\%), a bedside evaluation of the HIT test was considered questionable (difficult to understand). In one case, neither skew deviation nor HIT were clearly detectable.

Table I reports the cases in which a correlation between nystagmus direction and HIT were impossible, either for a "flat" nystagmus or for a HIT that was difficult to interpret by bedside examination. In total, 19 of 65 cases were not comparable.

Table II reports the 46 cases in which a correlation between nystagmus direction and HIT were possible.

In 43 of the remaining 46 cases, nystagmus tilt was congruent with HIT: 8 cases were of the central type (downhill nystagmus and normal HIT), and 35 of the peripheral type (uphill nystagmus and pathological HIT) (Table II).

In three cases, there was no congruence between the two tests.

In the two cases of negativity of HIT, the presence of "covert saccades" must be taken into account. In the case in which the HIT was abnormal, vertigo had been lasting for about two weeks, and thus it can be argued that a compensation of skew deviation was present. Keeping HIT as the gold standard, testing for nystagmus tilt allowed to obtain $80 \%$ sensitivity and $97 \%$ specificity.

\section{Discussion}

Overall, the results are suggestive for a close relationship between the OTR test and HIT.

Table I. If HIT is ambiguous (difficult to understand) or the spontaneous nystagmus beats strictly on the horizontal plane (or both) the results are not comparable. In our series, this occurred in 19 of 65 cases.

\begin{tabular}{|c|c|c|c|c|c|c|}
\hline Case $\mathrm{N}$ & Gender & Age & Direction of nystagmus & Hypertropic eye & HIT & Congruence \\
\hline 1 & M & 41 & Right & Right & $?$ & $?$ \\
\hline 2 & M & 58 & Right & Right & $?$ & $?$ \\
\hline 3 & $\mathrm{~F}$ & 58 & Right & Left & $?$ & $?$ \\
\hline 4 & $\mathrm{~F}$ & 46 & Right & Right & $?$ & $?$ \\
\hline 5 & M & 55 & Right & Right & $?$ & $?$ \\
\hline 6 & M & 72 & Right & $=$ & - & $?$ \\
\hline 7 & $\mathrm{~F}$ & 51 & Left & $=$ & - & $?$ \\
\hline 8 & M & 48 & Left & $=$ & + & $?$ \\
\hline 9 & M & 77 & Right & $=$ & + & $?$ \\
\hline 10 & M & 58 & Right & $=$ & $?$ & $?$ \\
\hline 11 & $\mathrm{~F}$ & 46 & Left & Left & $?$ & $?$ \\
\hline 12 & $M$ & 55 & Right & Right & $?$ & $?$ \\
\hline 13 & $\mathrm{~F}$ & 58 & Right & Right & $?$ & $?$ \\
\hline 14 & $\mathrm{~F}$ & 49 & Right & $=$ & - & $?$ \\
\hline 15 & $\mathrm{~F}$ & 44 & Left & $=$ & - & $?$ \\
\hline 16 & $F$ & 21 & Left & $=$ & + & $?$ \\
\hline 17 & $M$ & 79 & Left & $=$ & - & $?$ \\
\hline 18 & $M$ & 78 & Left & Left & $?$ & $?$ \\
\hline 19 & $\mathrm{~F}$ & 66 & Right & $=$ & + & $?$ \\
\hline
\end{tabular}


Table II. Comparing the plane of nystagmus (directed toward the hypertropic eye, "Uphill",or directed to the hypotropic eye, "Downhill") with HIT, chosen as the "gold standard", a close relation appears between the results of the two tests. Only in three cases was equivalency lacking ( $n=1 ; n=17 ; n=37)$. In the first two cases, this was attributed to "covert" saccades or a bias in execution of HIT. In the last case, a compensation of macular deficit seems possible since nystagmus was present for about two weeks.

\begin{tabular}{|c|c|c|c|c|c|c|}
\hline Case $\mathrm{N}$ & Gender & Age & Direction of nystagmus & Hypertropic eye & HIT & Congruence \\
\hline 1 & $\mathrm{~F}$ & 66 & Left & Right & + & No \\
\hline 2 & $\mathrm{~F}$ & 67 & Left & Left & + & Yes \\
\hline 3 & M & 56 & Left & Left & + & Yes \\
\hline 4 & M & 62 & Left & Left & + & Yes \\
\hline 5 & M & 42 & Left & Left & + & Yes \\
\hline 6 & $\mathrm{~F}$ & 72 & Left & Right & - & Yes \\
\hline 7 & $\mathrm{~F}$ & 52 & Right & Right & + & Yes \\
\hline 8 & $\mathrm{~F}$ & 74 & Right & Right & + & Yes \\
\hline 9 & $\mathrm{~F}$ & & Right & Left & - & Yes \\
\hline 10 & M & 72 & Left & Right & - & Yes \\
\hline 11 & $\mathrm{~F}$ & 59 & Right & Right & + & Yes \\
\hline 12 & $\mathrm{~F}$ & 85 & Right & Right & + & Yes \\
\hline 13 & $M$ & 41 & Left & Left & + & Yes \\
\hline 14 & $M$ & 21 & Left & Left & + & Yes \\
\hline 15 & $\mathrm{~F}$ & 40 & Right & Right & + & Yes \\
\hline 16 & $\mathrm{~F}$ & 53 & Right & Right & + & Yes \\
\hline 17 & $M$ & 72 & Left & Left & - & No \\
\hline 18 & $\mathrm{~F}$ & 69 & Left & Left & + & Yes \\
\hline 19 & $M$ & 53 & Left & Left & + & Yes \\
\hline 20 & $\mathrm{~F}$ & 66 & Left & Left & + & Yes \\
\hline 21 & $M$ & 55 & Right & Right & + & Yes \\
\hline 22 & $M$ & 41 & Right & Right & + & Yes \\
\hline 23 & $M$ & 35 & Left & Left & + & Yes \\
\hline 24 & $M$ & 56 & Left & Left & + & Yes \\
\hline 25 & $M$ & 91 & Right & Right & + & Yes \\
\hline 26 & $M$ & 42 & Left & Left & + & Yes \\
\hline 27 & $\mathrm{~F}$ & 52 & Right & Right & + & Yes \\
\hline 28 & $\mathrm{~F}$ & 79 & Right & Right & + & Yes \\
\hline 29 & $\mathrm{~F}$ & 74 & Right & Right & + & Yes \\
\hline 30 & $M$ & 39 & Right & Right & + & Yes \\
\hline 31 & $M$ & 62 & Left & Left & + & Yes \\
\hline 32 & $\mathrm{~F}$ & 69 & Right & Left & - & Yes \\
\hline 33 & $M$ & 62 & Left & Left & + & Yes \\
\hline 34 & $M$ & 42 & Left & Left & + & Yes \\
\hline 35 & $\mathrm{~F}$ & 72 & Left & Right & - & Yes \\
\hline 36 & $\mathrm{~F}$ & 42 & Right & Right & + & Yes \\
\hline 37 & $M$ & 64 & Left & Left & - & No \\
\hline 38 & $\mathrm{~F}$ & 73 & Left & Left & + & Yes \\
\hline 39 & $\mathrm{~F}$ & 70 & Left & Right & - & Yes \\
\hline 40 & $\mathrm{~F}$ & 57 & Left & Left & + & Yes \\
\hline 41 & $\mathrm{~F}$ & 65 & Right & Right & + & Yes \\
\hline 42 & $M$ & 84 & Right & Right & + & Yes \\
\hline 43 & $\mathrm{~F}$ & 62 & Right & Left & - & Yes \\
\hline 44 & $\mathrm{~F}$ & 65 & Right & Right & + & Yes \\
\hline 45 & $M$ & 60 & Left & Right & - & Yes \\
\hline 46 & $M$ & 66 & Left & Left & + & Yes \\
\hline
\end{tabular}


A nystagmus directed toward the healthy side associated with a peripheral skew deviation beats slightly uphill, as a consequence of hypotropia of the unwell side eye.

A nystagmus directed toward the healthy side associated with a central skew deviation beats slightly downhill, as a consequence of hypotropia of the healthy side eye.

A nystagmus originated by a disfacilitating cerebellar mechanism beats slightly downhill as a consequence of the presence of a central skew deviation.

If otherwise the utricular component is lacking (utricular maculae are spared), the nystagmus direction is fairly horizontal and no information can be argued about nystagmus origin: in our series, this is a fairly uncommon situation.

In case of doubt, the inter-pupillary plane can be obtained from a photograph and measured. In a previous work, the normal values of deviation were not over 2.2 degrees ${ }^{12}$. The examiner most often has the exact perception of the situation just by observing the patient who is sitting and holding glasses alone: thus, this test is actually a bedside test, confirming HIT or replacing it in cases of ambiguity (not collaborating patients, covert saccades, etc.).

Frenzel glasses are preferable to videooculoscopy because cameras are not likely to be perfectly horizontal, but inspection without any kind of device is possible if, of course, nystagmus is not completely inhibited by fixation. On the basis of our results, it would appear that in the majority of cases utriculus is damaged along with the canal: only in $15 \%$ of cases did we find spared utricular maculae in spontaneous nystagmus. This is associated with a strictly horizontal nystagmus (not uphill, not downhill).

\section{Conclusions}

At present, no bedside test alone is able to diagnose the lesion site in every case of spontaneous nystagmus. HIT is a resource, but not always it is easy to perform and to interpret. Nevertheless, a prompt diagnosis is required in case of acute vertigo and spontaneous nystagmus: in these cases, a decision is taken on the base of clinical examination (magnetic resonance imaging is not always available and not entirely reliable at the early stages).

As each clue can be useful, observation of the plane on which the nystagmus beats can be convenient as not time consuming or tedious for the patient.

It might be suggested that nystagmus be classified in three groups:

1. uphill nystagmus (to be considered as peripheral);
2. downhill nystagmus (to be considered as central);

3. plane nystagmus (nystagmus is beating right in plane, not rising nor falling), not meaningful, as utricular macula is likely not concerned.

\section{References}

1 Teggi R, Manfrin M, Balzanelli C, et al. Point prevalence of vertigo and dizziness in a sample of 2672 subjects and correlation with headaches. Acta Otorhinolaryngol Ital 2016;36:215-9.

2 Kattah JC, Talkad AV, Wang DZ, et al. Newman-Toker DE HINTS to diagnose stroke in the acute vestibular syndrome: three-step bedside oculomotor examination more sensitive than early mri diffusion-weighted imaging. Stroke 2009;40:3504-10.

3 Halmagyi GM, Curthoys IS. A clinical sign of canal paresis. Arch Neurol 1988;45:737-9.

4 Vanni S, Pecci R, Casati C, et al. STANDING, a four-step bedside algorithm for differential diagnosis of acute vertigo in the Emergency Department. Acta Otorhinolaryngol Ital 2014;34:419-26.

5 Nelson JA, Viirre E. The clinical differentiation of cerebellar infarction from common vertigo syndromes. West J Emerg Med 2009;10:273-7.

6 Cnyrim CD, Newman-Toker D, Karch C, et al. Bedside differentiation of vestibular neuritis from central "vestibular pseudoneuritis”. Neurol Neurosurg Psychiatry 2008;79:458-60.

7 Lee H, Sohn SI,Cho JW, et al. Cerebellar infarction presenting isolated vertigo. Neurology 2006;67:1178-83.

8 Tjernström F, Nyström A, Magnusson M. How to uncover the covert saccade during the head impulse test. Otol Neurotol 2012;33:1583-5.

9 Westheimer G, Blair SM. The ocular tilt reaction - a brainstem oculomotor routine. Invest Ophtal 1975;14: 833-9.

10 Mossman S, Halmagyi GM. Partial ocular tilt reaction due to unilateral cerebellar lesion. Neurology 1997;49:491-3.

11 Eekhof JA, de Bock GH, de Laat JA, et al. The whispered voice: The best test for screening for hearing impairment in general practice? Br J Gen Pract 1996;46:473-4.

12 Gufoni M. Le manifestazioni cliniche della VPPB del canale laterale. In: La Vertigine Parossistica Posizionale (Benigna): Stato dell'arte. LV Raduno del Gruppo Alta Italia di Otorinolaringoiatria e Chirurgia Cervico-Facciale. Presidente Prof. D. Nuti. Siena 5 Dicembre 2009. 